\section{Referral patterns and diagnoses in women attending a urodynamic unit}

\author{
Declan P Keane, Seumas D Eckford, \\ Angela M Shepherd, Paul Abrams
}

Urodynamic Unit, Southmead Hospital, Bristol BS10 5NB

Declan P Keane, research registrar

Seumas D Eckford, research registrar

Angela M Shepherd,

associate specialist

Paul Abrams, consultant urologist

Correspondence to:

Dr Keane.

BMF 1992;305:808

Although it is recognised that the prevalence of urinary incontinence increases with age, ${ }^{1}$ it is not known whether this is mirrored by a similar increase in referral for urodynamic studies. The aim of this study was to determine the association with age of referral patterns and urodynamic diagnoses in women with urinary incontinence.

\section{Patients, methods, and results}

We reviewed the urodynamic diagnoses of 2845 women seen over 10 years (1981-90). The review included all patients with symptoms of urinary incontinence who were neurologically intact and had no history of surgery for incontinence. All patients were examined by filling and voiding cystometry, and the urodynamic diagnosis assigned to each patient was based on International Continence Society definitions.

The number of patients referred in each age group and their urodynamic diagnoses are shown in the table. Review of the referral pattern indicates that the peak age was in the perimenopausal years, $1548(54 \%)$ of the patients being in the $36-55$ year age range. The most striking feature was the small number of patients attending in the older age groups, only 395 (14\%) patients being over the age of 66 . That age group has a reported prevalence of incontinence of $11 \cdot 6 \%$.

The trend in urodynamic diagnosis showed that genuine stress incontinence was the most common diagnosis overall, being found in $1774(62 \%)$ of the patients. These included patients with pure genuine stress incontinence and those with mixed incontinence. The percentage with genuine stress incontinence increased steadily into the perimenopausal years and thereafter remained relatively constant. There was a gradual increase in detrusor instability with age, ranging from $16 \%$ in the $16-25$ age group to $45 \%$ in the

Age related referrals for urodynamic investigations and urodynamic diagnoses applied. Figures are numbers of referrals (percentage of age group with specific diagnoses in parentheses)

\begin{tabular}{lrrrrrrrr}
\hline & $16-25$ & $26-35$ & $36-45$ & $46-55$ & $56-65$ & $66-75$ & $\geqslant 76$ & Total \\
\hline Genuine stress incontinence & $11(17)$ & $142(40)$ & $418(52)$ & $407(55)$ & $236(49)$ & $148(48)$ & $39(46)$ & 1401 \\
Detrusor instability & $3(5)$ & $64(18)$ & $98(12)$ & $93(13)$ & $67(14)$ & $50(16)$ & $13(15)$ & 388 \\
Mixed & $7(11)$ & $15(4)$ & $89(11)$ & $101(14)$ & $81(17)$ & $55(18)$ & $25(30)$ & 373 \\
Hypersensitive & 0 & $23(6)$ & $19(2)$ & $12(2)$ & $13(3)$ & $5(2)$ & 0 & 72 \\
Normal & $44(67)$ & $113(32)$ & $184(23)$ & $127(16)$ & $83(17)$ & $53(16)$ & $7(9)$ & 611 \\
\hline Total & 65 & 357 & 808 & 740 & 480 & 311 & 84 & 2845 \\
\hline
\end{tabular}

over 75 group, again combining those with pure instability and those with mixed incontinence.

An interesting feature was the number of normal urodynamic findings in young women. The percentage with normal findings decreased with age from $67 \%$ in the $16-25$ age group to $9 \%$ in the over 76 age group. Overall 611 (21\%) patients had normal urodynamic findings.

\section{Comment}

The value of urodynamic investigations in women with lower urinary tract dysfunction is now well established, ${ }^{3}$ based on their reliability and reproducibility ${ }^{4}$ and the low morbidity associated with their performance. ${ }^{5}$ Thus the most striking feature of our study was the scarcity of patients attending in the geriatric age group. We feel that urodynamics is more relevant in an elderly population in whom sensory deficits and poor memory combine to produce a substandard history, these being the patients more likely to have a specific urodynamic abnormality explaining their symptoms as our study shows.

The trends in urodynamic diagnoses with age show that there was a gradual increase in detrusor instability with age, but genuine stress incontinence increased only up to the menopause. Although we still believe that genuine stress incontinence increases with age, the apparent peak of this condition in the 36-55 age group represents a time when the condition is more socially or physically restricting on the patient.

Our results showed that $21 \%$ of the patients had no urodynamic abnormality on conventional studies. This was partially due to the artificial nature of the test and the confined time available to perform the studies. As a result we now rely on ambulatory urodynamics in patients who have normal conventional studies despite having marked urinary symptoms. These studies are more physiological as they depend on a natural bladder fill technique and allow bladder function to be studied over a longer time.

Our study suggests that the low referral pattern in older women needs to be addressed, and we feel the onus for this rests with primary health care workers. Improved awareness of continence and urodynamic services is also required in order that patients will more readily refer themselves for treatment.

1 Thomas TM, Plymat KR, Blannin J, Meade JW. Prevalence of urinary incontinence. BMF 1980;281:1243-5.

2 Abrams P, Blaivas JG, Stanton SL, Anderson JT. The standardization of terminology of lower urinary tract function. Br $\mathcal{J}$ Obstet Gynaecol 1990; suppl 6:1-16.

Versi E, Cardozo L, Anand D, Cooper D. Symptom analysis for the diagnosis of genuine stress incontinence. Br $\mathcal{F}$ Obstet Gynaecol 1991;98:815-9.

4 Sorensen S, Gregersen H, Sorensen SM. Long term reproducibility of urodynamic investigations in healthy fertile females. Scand $\mathcal{F}$ Urol Nephrol urodynamic invest

5 Carter PG, Lewis P, Abrams P. Urodynamic morbidity and dysuria prophylaxis. Brf Urol 1991;67:40-1

(Accepted 20 August 1992)
Dr Rodger.

BMF 1992;305:808-9

\section{Drugs and the exercise test}

\author{
K W Muir, J C Rodger, J S DeBono, \\ $\mathrm{H}$ McDonald, J B Irving
}

Cardiac and other drugs are recognised to interfere with the interpretation of exercise tests. ${ }^{12}$ A 1989 survey (unpublished) suggested that there might be important differences between Scottish hospitals in whether or not drugs are discontinued before exercise testing. This prompted a more detailed reappraisal.

\section{Methods and results}

Questionnaires were sent to 30 teaching and district general hospitals in Scotland. Replies were received from all and were followed up by telephone questioning of the consultant responsible for the exercise service. Details were sought of the hospital policy on stopping drugs and, when there was none, on the consultant's personal policy. Specific inquiry was made regarding digoxin, $\beta$ blockers, calcium antagonists, nitrates, and antihypertensive therapy and consultants were invited to suggest any other drug which they would consider stopping. Duration of stopping, whether the decision was affected by the indication for testing, and indications 
Monklands District General Hospital, Airdrie, Lanarkshire ML6 0JS

$\mathrm{K}$ W Muir, senior house officer $\mathrm{J}$ C Rodger, consultant physician

J S DeBono, senior house officer

H McDonald, cardiology technician

St John's Hospital at Howden, Livingstone, West Lothian

J B Irving, consultant physician for exercise thallium scintigraphy were requested.

Fourteen hospitals (two teaching, 12 district) had a hospital policy on stopping drugs. In the remainder (eight teaching, eight district) the decision was left to the referring physician. Hospital policies and, for those with no policy, the practice of individual consultants are detailed in the table.

Of those 18 hospitals or individuals stopping $\beta$ blockers, the periods for which they were stopped were 48 hours (12), 24 hours (two), or the day of the test (four). Calcium antagonists and nitrates were each discontinued on the day of testing by three, and 12 hours before by one. One other unit stopped both classes of drugs only in patients being exercised for the diagnosis of chest pain. Digoxin was not stopped before exercise in any unit, but one hospital performed exercise thallium scintigraphy in preference to electrocardiography. Thirteen of the 20 hospitals with access to nuclear cardiology facilities considered digoxin therapy or repolarisation abnormalities on the electrocardiogram as potential indications for thallium scanning.

\section{Comment}

Diuretic induced hypokalaemia, tricyclic antidepressants, phenothiazines, and antiarrhythmic drugs all produce repolarisation abnormalities which may confound ST segment analysis. Existing guidelines recognise this ${ }^{12}$ yet no hospital discontinued these drugs. With one exception all hospitals performed exercise electrocardiography in patients on digoxin. Digoxin causes dose dependent ST depression during exercise, and the incidence of digoxin induced false positive test results increases with age. Discontinuation for 10 days before testing is therefore recommended. Recent recommendations that exercise thallium scintigraphy should be utilised in patients with repolarisation abnormalities in preference to exercise electrocardiography ${ }^{3}$ were followed inconsistently. The prognostic validity of tests performed while

Hospital $(H)$ and individual (I) policies on stopping drugs $(n=30)$ on drugs causing repolarisation changes, including digoxin, has not been conclusively proved. $\beta$ Blockers, nitrates, and calcium antagonists all prolong the time to exercise limiting angina and ST segment depression and alter heart rate and blood pressure responses. Wide interindividual variation of these effects occurs, and in combination therapy responses are unpredictable. ${ }^{4} \beta$ Blockade may invalidate the prognostic value of the test.

The potential problems of exercise test interpretation in patients on drugs are widely disregarded in Scottish hospitals. In practice, greater variation will occur than is apparent from the table since most hospitals leave decisions on discontinuation of drugs to the discretion of individuals. Teaching hospitals surprisingly provide no lead in the formulation of policy. On the basis of our results it is improbable that tests performed in different hospitals are comparable. Since patients are selected for coronary angiography largely on the basis of exercise test results there are important implications for resource management. More detailed audit of this area is required.

We have no reason to believe that practice differs in the rest of the United Kingdom. Until information on the prognostic value of exercise testing in the setting of drug therapy is available it may be preferable to discontinue all drug treatment before exercise testing.

1 Schlant RC, Blomqvist CG, Brandenburg RO, Debusk R, Ellestad MH, Fletcher GF, et al. Guidelines for exercise testing: a report of the joint American College of Cardiology/American Heart Association Task Force on Assessment of Cardiovascular Procedures. Circulation 1986;74:653-67A

2 Lollagen H, Ulmer HV, Crean P. Recommendations and standard guidelines for exercise testing: a report of the task force on ergonometry. Eur Heart $\mathcal{Y}$ $1988 ; 9(\mathrm{~K}): 3-37$.

3 American College of Physicians. Efficacy of exercise thallium-201 scintigraphy in the diagnosis and prognosis of coronary artery disease. Ann Intern Med 1990;113:703-4.

4 Akhras F, Jackson G. Efficacy of nifedipine and isosorbide mononitrate in combination with atenolol in stable angina. Lancet 1991;338:1036-9.

5 Curtis JL, Houghton JL, Patterson H, Koch G, Bradley DA. Adams KF. Propranolol therapy alters estimation of potential cardiovascular risk derived from submaximal post-infarction exercise testing. Am Heart $\mathcal{J} 1991$; 121: 1655-64.

(Accepted 11 August 1992)

\begin{tabular}{|c|c|c|c|c|c|c|c|c|c|c|}
\hline \multirow[b]{2}{*}{ Is drug stopped? } & \multicolumn{2}{|c|}{ Digoxin } & \multicolumn{2}{|c|}{ Calcium antagonists } & \multicolumn{2}{|c|}{ Nitrates } & \multicolumn{2}{|c|}{$\beta$ Blockers } & \multicolumn{2}{|c|}{ Antihypertensives } \\
\hline & $\mathrm{H}$ & I & $\mathrm{H}$ & I & $\mathrm{H}$ & I & $\mathrm{H}$ & I & $\mathrm{H}$ & I \\
\hline Never & 14 & 16 & 10 & 14 & 11 & 14 & 5 & 7 & 10 & 16 \\
\hline Always & 0 & 0 & 3 & 1 & 3 & 1 & 7 & 4 & 0 & 0 \\
\hline Diagnosis of chest pain only & 0 & 0 & 1 & 1 & 0 & 1 & 2 & 2 & 0 & 0 \\
\hline Other indications & 0 & 0 & 0 & 0 & 0 & 0 & 0 & 3 & 4 & 0 \\
\hline
\end{tabular}

\section{ONE HUNDRED YEARS AGO}

\section{IS SOFT MUSIC A CALMATIVE IN CASES OF FEVER?}

SIR, - In reference to Canon Harford's letter on the above, which appeared in the BRITISH MEDICAL JOURNAL of September 17th, I beg leave to endorse, as far as my observation will allow, his opinions therein stated. At the beginning of last winter I asked and obtained permission of the infirmary committee here to allow of a piano being placed in the institution with a view to experimenting on the soothing and curative effect of music in disease. A number of ladies formed themselves into a choir, and selected music, instrumental and vocal, of a kind calculated to soothe the suffering. Some of the members of the choir visited the infirmary every Friday afternoon for the purpose of testing its influence in that regard. Our infirmary, however, is a general one, and for that reason I cannot speak with any certainty of the precise class of cases mentioned by Canon Harford; nevertheless, we were so satisfied with the beneficial results obtained in dealing with general cases, that we feel compelled to continue on the same lines as those followed by us last winter. The cessation, or at least diminution, of pain in many instances has been most marked. Unfortunately it was not until early spring that I thought of employing the thermometer as a test before and after the administration of music in those cases where the temperature was abnormally high, so that I must refrain from publishing the particulars until I have made a more extended trial. Suffice it to say, however, that seven out of ten noted cases were benefited in so far as a reduction of temperature was recorded. In the case of one woman suffering from peritonitis, the temperature within the hour fell from $100^{\circ}$ to $99.2^{\circ}$. Later on I hope to tabulate my cases and record the result. - I am, etc.,

Helensburgh. J. EwING HUNTER, M.B. and C.M.

P.S. - We shall be grateful for any music Canon Harford may deem suitable for the purposes of trial.

(BMF 1892;ii;:923.) 